ORIGINAL ARTICLE

\title{
Effect of enteral administration of insulin on intestinal development and feeding tolerance in preterm infants: a pilot study
}

\section{R J Shulman}

\author{
R J Shulman, USDA/ARS \\ Children's Nutrition \\ Research Center, \\ Department of Pediatrics, \\ Baylor College of \\ Medicine, and Texas \\ Children's Hospital, \\ Houston, Texas, USA \\ Correspondence to: \\ Dr Shulman, 1100 Bates \\ St, Houston, TX 77030, \\ USA; \\ rshulman@bcm.tmc.edu \\ Accepted \\ 6 November 2001
}

Objective: To determine in a pilot study whether enteral administration of insulin to preterm infants (26-29 weeks of gestational age) would enhance gastrointestinal development and reduce feed intolerance without adverse effects.

Design: Eight preterm infants were given $4 \mathrm{U} / \mathrm{kg} /$ day insulin enterally from 4 to 28 days of age. Lactase activity was measured at 28 days of age, while measures of feed intolerance were made throughout the hospital stay. The results were compared with those of a matched historical cohort of 80 preterm infants.

Setting: Tertiary care, university affiliated hospital.

Main outcome measures: Lactase activity and feed intolerance.

Results: No adverse effects, such as hypoglycaemia, were observed after administration of insulin. The infants who received insulin had higher lactase activity and less feed intolerance than the controls $130 \%$ shorter time to full enteral feeds; fewer gastric residuals per infant).

Conclusions: These preliminary data suggest that enteral insulin administration may be of benefit in reducing feed intolerance in preterm infants. A randomised, blinded trial is warranted.
$\mathrm{F}$ eeding preterm infants is a formidable task because of their gastrointestinal (GI) immaturity. Previous studies have shown that a number of their GI functions are underdeveloped compared with those of the term infant. GI functions such as lactase activity and motor function undergo their most significant development during the last trimester. ${ }^{12}$ Animal studies have shown that maternal milk contains a number of factors that can enhance development of the immature GI tract. ${ }^{3}$ Of these, insulin is present in maternal milk at levels three to fourfold higher than in maternal blood. ${ }^{4}$

Insulin has been shown both in vitro and in vivo to accelerate a number of GI functions. ${ }^{5-9}$ More recently, enteral administration of insulin to newborn pigs and rats has been shown to enhance development of intestinal activity and growth. ${ }^{10-14}$

The present pilot study was carried out to determine whether enteral administration of insulin to preterm infants would enhance their gastrointestinal development and reduce feed intolerance. A large, randomised, placebo controlled trial would be required to irrefutably resolve this question. Before embarking on such an investigation, however, preliminary evidence must be obtained to show that insulin is efficacious, optimally in the form of a pilot trial such as the one conducted and described here, delineating the manifestations and magnitude of such an effect.

\section{MATERIALS AND METHODS}

\section{Study population}

Two groups of infants were compared. Eight insulin treated infants were enrolled during 1997. They were selected sequentially from the Texas Children's Hospital nursery by criteria used in a prospective feeding trial in 1992-1997. ${ }^{15}$ The infants recruited met the following criteria: 26-30 weeks gestation, determined by a combination of maternal dates and early antenatal ultrasound; gestational age agreement between the two methods of two weeks or less; appropriate size for gestational age; postnatal age $\leqslant 96$ hours; absence of major congenital malformations; and fraction of inspired oxygen $<0.60$ at 72 hours.

Matched control infant data were obtained from the prospective feeding trial performed in 1992-1997. Infants from the feeding trial were used as controls in order to obtain comprehensive data on a large number of infants.

Of the 171 infants enrolled in this feeding trial, 80 were found to match the insulin treated infants in terms of gestational age, birth weight, age at which feeds were started, proportion of feeds that were human milk, and feeding method (intermittent bolus every three hours).

The study was approved by the Baylor College of Medicine institutional review board for human subject research. Informed written consent was obtained from parents before enrolment.

\section{Study design}

Insulin treated infants received $1 \mathrm{U} / \mathrm{kg}$ regular human insulin (Humulin; Eli Lilly \& Co, Indianapolis, Indiana, USA) every six hours. The insulin was given through the nasogastric feeding tube, followed by the infant's usual feed. Insulin administration was begun at 4 days of age and continued to 28 days of age. The dose and duration were based on preliminary studies carried out in newborn pigs. ${ }^{12}$

\section{Feeding protocol}

Feeds were begun in both groups of infants when they were clinically stable (about 10 days of age). The initial feeding volume was $20 \mathrm{ml} / \mathrm{kg} / \mathrm{day}$ and the volume was increased by that amount daily until complete enteral feeding was achieved. ${ }^{15}$ Parenteral nutrition was used until the infants achieved complete enteral feeds, and was adjusted to provide a total intake (enteral and parenteral) of $120 \mathrm{kcal} / \mathrm{kg} /$ day. ${ }^{15}$ The infants received either human milk or Enfamil Premature Formula (Mead-Johnson Nutritional Division, Evansville, Indiana, USA) if the mothers had inadequate milk production. Management of the infants was at the discretion of the attending neonatologists without input from the investigator. 
Table 1 Clinical characteristics of preterm infants given insulin or not (controls)

\begin{tabular}{lll}
\hline & $\begin{array}{l}\text { Insulin } \\
\text { group ( } \mathrm{n}=8)\end{array}$ & $\begin{array}{l}\text { Control } \\
\text { group } \\
(\mathrm{n}=80)\end{array}$ \\
\hline Gestational age (weeks) & $27.8(2.5)$ & $27.8(1.2)$ \\
Birth weight (g) & $973(310)$ & $1042(172)$ \\
Age feeds begun (days) & $9.9(4.3)$ & $11.3(5.2)$ \\
Percentage of feeds with human milk & $30(32)$ & $43(40)$ \\
Age at lactase measurement (days) & $29(3)$ & $29(4)$ \\
Antenatal glucocorticoids (n) & $4(50 \%)$ & $45(56 \%)$ \\
\hline Values are mean (SD). & & \\
\hline
\end{tabular}

Standard care of infants in the nursery did not change appreciably over the observation period. In addition, the large number of neonatologists at the institution helps to ensure that no one doctor has an inordinate influence on patient care.

\section{Effect of insulin on blood glucose}

To determine the effects of enteral insulin on serum glucose concentration, they were measured at 0,30 , and 90 minutes after the first, second, and fifth doses of insulin.

\section{Measurement of lactase activity}

Intestinal lactase activity in both groups of infants was determined at 28 days of age using the method of Weaver et al. ${ }^{16}$ This method has been validated by comparison with direct measurements of lactase activity in biopsy specimens of small intestine in the same patients. ${ }^{17}{ }^{18}$ In addition, changes in the ratio correlate with clinical observations on disaccharidase activity. ${ }^{17}{ }^{18} \mathrm{I}$ have made similar observations in newborn pigs (unpublished data). To account for any variation in the intake of lactose and lactulose, the lactulose/lactose ratio was expressed as that measured in the urine versus that measured in the milk. ${ }^{19}$ Thus the higher the lactase activity, the higher the urine to milk ratio of lactulose/lactose.

The lactulose/lactose solution was administered for a total of 30 hours. ${ }^{16}$ During the last six hours, all urine was collected continuously as previously described, ${ }^{19}$ and stored at $-20^{\circ} \mathrm{C}$ with $0.1 \mathrm{ml}$ sodium merthiolate until analysed. ${ }^{16}{ }^{19}$

\section{Measures of feeding intolerance}

Measures of feed intolerance were monitored throughout the hospital stay for both groups. For the insulin treated infants and the controls, decisions to withhold feeds because of feed intolerance were made by the attending doctor according to a published algorithm. ${ }^{20}$ Gastric residuals were determined by aspiration of the gastric contents from the indwelling orogastric tube every three hours in all infants. Gastric residuals were tabulated as $\geqslant 2 \mathrm{ml} / \mathrm{kg}$ or $>50 \%$ of a three hour feeding volume.

\section{Analyses}

Blood glucose was measured using an autoanalyser. Lactose and lactulose in milk and urine were determined using a modification of the method of Catassi et $a l^{21}$ as described previously. ${ }^{19}$

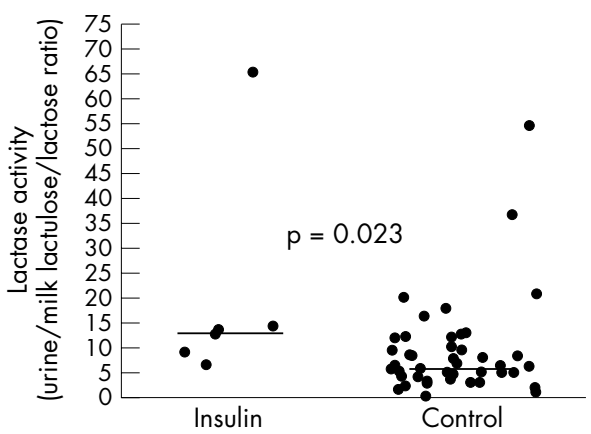

Figure 1 Scattergram of lactase activity at 28 days of age in the insulin and control groups $(n=6$ and 43 respectively; samples could not be obtained from all infants for various reasons, such as the parents and/or attending doctor requesting that the test was not performed or the infants were unstable). The horizontal lines represent the median values. Lactase activity was determined using the urine/milk lactulose/lactose ratio.

\section{Data analysis}

Differences between groups were compared using Student's $t$ test. Mann-Whitney analysis was used for data not normally distributed. The data are expressed as mean (SD) or median and range as appropriate.

\section{RESULTS}

The clinical characteristics of the insulin treated and control infants were well matched (table 1). There was no evidence of hypoglycaemia after the first, second, or fifth dose of insulin (baseline: 8.9 (3.2) mmol/l; $30 \mathrm{~min}: 9.7$ (3.1) mmol/l; $90 \mathrm{~min}$ : 9.6 (2.9) mmol/l; mean (SD) for first dose; other data not shown). No untoward effects of the insulin treatment were observed.

At 28 days of age, median lactase activity was higher in the insulin group than in the control group (table 2; fig 1). Lactase measurements were available for six of the eight insulin treated infants and 43 of the controls. The insulin treated infants achieved full enteral feeds earlier and at a younger age than did the controls (table 2).

The insulin treated infants had fewer gastric residuals than the control infants (table 2). This was significant for the number of residuals $>2 \mathrm{ml} / \mathrm{kg}$ and borderline significant for residuals that were $>50 \%$ of the volume of the previous feed (table 2). There were no differences between groups with respect to the age at discharge (75 (30) days $v 81$ (33) insulin $v$ control).

\section{DISCUSSION}

A large part of the morbidity associated with preterm birth is related to feed intolerance. Given that term infants rarely experience feeding difficulties, it is accepted that feed intolerance in the preterm infant is related to GI immaturity. ${ }^{20}$ Although various feeding trials and treatments have attempted to ameliorate feed intolerance, they have met with limited success.

Table 2 Lactase activity and measures of feeding intolerance in preterm infants given insulin or not (controls)

\begin{tabular}{llll}
\hline & Insulin group $(\mathbf{n}=8)$ & Control group $(\mathbf{n}=80)$ & $\mathrm{p}$ Value \\
\hline Lactase activity & $13.3(6.7-65.4)$ & $6.5(0.43-54.76)$ & 0.023 \\
Age at full enteral feeds (days) & $21(6)$ & $31(15)$ & 0.004 \\
Days to full enteral feeding & $11(6)$ & $20(16)$ & 0.007 \\
Mean number per infant & $22(17)$ & $54(44)$ & 0.001 \\
$\quad$ Gastric residuals $>2 \mathrm{ml} / \mathrm{kg}$ & $2.4(3.4)$ & $5.2(7.0)$ & 0.07 \\
$\quad$ Gastric residuals $>50 \%$ of previous feeding & & & \\
\hline Values are median (range) or mean (SD). & &
\end{tabular}


In vitro and in vivo work in animals documents the ability of insulin to enhance GI development and function. ${ }^{5-9}$ A growing body of literature from studies in various animal species supports the earlier observation in newborn pigs that administration of enteral insulin also accelerates GI development. ${ }^{10-14}$ Insulin is attractive as an agent to enhance GI development in the preterm infant. It is normally present in human milk at high concentrations relative to maternal blood. ${ }^{4}$ It is not absorbed systemically to any significant degree as measured by changes in blood sugar in this study and in a previous investigation. ${ }^{22}$ It is inexpensive and readily available.

The results of this study suggest that enteral administration of insulin to preterm infants enhances GI function, as measured by increased lactase activity (table 2; fig 1). Previous studies have documented the importance of lactase activity and lactose digestibility in reducing feed intolerance in preterm infants. ${ }^{123}$ This is one possible explanation for the finding that the insulin treated infants achieved full enteral feeds earlier than the control infants and experienced less feed intolerance, as indicated by their lower incidence of increased gastric residuals. The explanation for the outliers in lactase activity in both groups (fig l) is not clear. The outlier in the insulin group was remeasured at 40 days of age and the value was even higher, suggesting that the value at 28 days of age was not an error. Presumably, this variation in lactase activity in both groups reflects the variability in intestinal maturation among infants. It may explain, in part, why different infants follow such diverse clinical courses.

A limitation of this preliminary study is the retrospective nature of the control infants. However, management of the insulin treated and control infants was similar as it was controlled by nursery protocol. ${ }^{20}$ Further, the investigator had no input into the management of any infants as this was in the hands of the various attending neonatologists. Recent studies have documented the value of similar case-controlled investigations. ${ }^{24-26}$

The goal of this study was to ascertain whether there was evidence that insulin is efficacious in enhancing GI development and reducing feed intolerance in preterm infants. Given that these pilot data support this hypothesis, I suggest that a randomised, placebo controlled trial is indicated. Although I observed no ill effects during the course of insulin administration or throughout the remainder of the hospital stay, potential long term effects such as the development of insulin antibodies or the prevention of diabetes (as has been observed in animal models) must be explored in future trials. ${ }^{27}$ Although previous studies suggested that hypoglycaemia was unlikely to occur, a much larger number of infants would need to be studied to exclude the possibility. Therefore enteral insulin should not be used outside of a study setting.

\section{ACKNOWLEDGEMENTS}

This study was supported by the Daffy's Foundation and the USDA/ARS under Cooperative Agreement No 58-6250-1-003. This work is a publication of the USDA/ARS Children's Nutrition Research Center, Department of Pediatrics, Baylor College of Medicine and Texas Children's Hospital, Houston, TX. The contents of this publication do not necessarily reflect the views or policies of the USDA, nor does mention of trade names, commercial products, or organisations imply endorsement by the US Government.

\section{REFERENCES}

1 Henning SJ, Rubin DC, Shulman RJ. Ontogeny of the intestinal mucosa. In: Johnson LR, ed. Physiology of the gastrointestinal tract. New York: Raven Press, 1994

2 Berseth CL, Nordyke C. Enteral nutrients promote maturation of intestinal motor activity in preterm infants. Am J Physiol 1993;264:G1046-51.

3 Koldovsky O, Thornburg W. Hormones in milk. J Pediatr Gastroenterol Nutr 1987:6:172-96.

4 Slebodzinski AB, Nowak J, Gawecka H, et al. Thyroid hormones and insulin in milk: a comparative study. Endocrinology Experiment 1986;20:247-55.

5 Buts J-P, de Keyser N, Kolanowski J, et al. Hormonal regulation of the rat small intestine: responsiveness of villus and crypt cells to insulin during the suckling period and unresponsiveness after weaning. Pediatr Res 1990;27:161-4.

6 Albert V, Barkla D, Young GP. Serum-free organ culture of suckling rat jejunum: effect of regulatory hormones. In Vitro Cell Dev Biol Anim 1994;30:443-9.

7 Simon PM, Kedinger M, Raul F, et al. Organ culture of suckling rat intestine: comparative study of various hormones on brush border enzymes. In Vitro 1982;18:339-46.

8 Arsenault $\mathbf{P}$, Menard D. Insulin influences the maturation and proliferation of suckling mouse intestinal mucosa in serum-free organ culture. Biol Neonate 1984;46:229-36.

9 Menard D, Malo C, Calvert R. Insulin accelerates the development of intestinal brush border hydrolytic activities of suckling mice. Dev Biol 1981;85:150-5.

10 Shulman RJ. Oral insulin increases small intestinal mass and disaccharidase activity in the newborn miniature pig. Pediatr Res 1990;28:171-5.

11 Harada E, Syuto B. Precocious cessation of intestinal macromolecular transmission and sucrase development induced by insulin in adrenalectomized suckling rat. Comp Biochem Physiol 1991;99:327-31.

12 Shulman RJ, Tivey DR, Sunitha I, et al. Effect of oral insulin on lactase activity, mRNA, and posttranscriptional processing in the newborn pig. $J$ Pediatr Gastroenterol Nutr 1992;14:166-72.

13 al-Majali AM, Asem EK, Lamar C, et al. Insulin modulates intestinal response of suckling mice to the Escherichia coli heat-stable enterotoxin. Adv Exp Med Biol 1999;473:1 13-23.

14 Buts JP, De Keyser N, Sokal EM, et al. Oral insulin is biologically active on rat immature enterocytes. J Pediatr Gastroenterol Nutr 1997;25:230-2.

15 Schanler RJ, Shulman R, Lau C, et al. Feeding strategies for premature infants: randomized trial of gastrointestinal priming and tube-feeding method. Pediatrics 1999;103:434-9.

16 Weaver LT, Laker MF, Nelson R. Neonatal intestinal lactase activity. Arch Dis Child 1986:61:896-9.

17 Noone C, Menzies IS, Banatvala JE, et al. Intestinal permeability and lactose hydrolysis in human rotaviral gastroenteritis assessed simultaneously by non-invasive differential sugar permeation. Eur J Clin Invest 1986;16:217-25.

18 Maxton DG, Cart SD, Menzies IS. Combined assessment of intestinal disaccharidases in congenital asucrasia by differential urinary excretion. J Clin Pathol 1990;43:406-9.

19 Shulman RJ, Schanler RJ, Lau C, et al. Early feeding, feeding tolerance, and lactase activity in preterm infants. J Pediatr 1998;133:645-9.

20 Schanler RJ. The low-birth-weight infant. In: Nutrition in pediatrics: basic science and clinical application. 2nd ed. Walker WA, Watkins JB, eds. Hamilton: BC Decker Inc, 1996:392-412.

21 Catassi C, Bonucci A, Coppa GV, et al. Intestinal permeability changes during the first month: effect of natural versus artificial feeding. J Pediatr Gastroenterol Nutr 1995;21:383-6.

22 Znumenacek K, Pribylova H. Effect of glucose and insulin application on blood sugar of the newborn. Czechoslovak Pediatry 1963;18:104-19.

23 Griffin MP, Hansen JW. Can the elimination of lactose from formula improve feeding tolerance in premature infants? J Pediatr 1999;135:587-92.

24 Benson K, Hartz AJ. A comparison of observational studies and randomized, controlled trials. N Engl J Med 2000;342:1878-86.

25 Concato J, Shah N, Horwitz RI. Randomized, controlled trials, observational studies, and the hierarchy of research designs. N Engl J Med 2000;342: 1887-92

26 Stuart J, Pocock SJ, Elbourne DR. N Engl J Med 2000;342: 1907-9.

27 Vaarala $\mathrm{O}$. Gut and the induction of immune tolerance in type 1 diabetes. Diabetes Metab Res Rev 1999;15:353-61. 